\title{
A Pro12Ala polymorphism in the human peroxisome proliferator-activated receptor- $\gamma 2$ is associated with combined hyperlipidaemia in obesity
}

Michael M Swarbrick, Caroline M L Chapman, Brendan M McQuillan ${ }^{1}$, Joseph Hung ${ }^{2}$, Peter L Thompson ${ }^{1}$ and John P Beilby

Department of Clinical Biochemistry, PathCentre, Nedlands, Western Australia 6009, Australia, ${ }^{1}$ Sir Charles Gairdner Campus of the Heart Research Institute of Western Australia, Nedlands, Western Australia 6009, Australia and ${ }^{2}$ Department of Medicine, University of Western Australia, Nedlands, Western Australia 6009, Australia

(Correspondence should be addressed to J P Beilby; Email: john.beilby@health.wa.gov.au)

\begin{abstract}
Objective: Peroxisome proliferator-activated receptor- $\gamma 2$ (PPAR $\gamma 2)$ is an important regulator of adipose tissue metabolism and insulin sensitivity. The aim of this investigation was to determine whether a PPAR $\gamma 2$ Pro12Ala polymorphism was associated with cardiovascular risk factors (obesity, blood pressure, diabetes and blood lipids) in Western Australian Caucasians $(n=663)$.

Design: Subjects were selected from two population studies (the Carotid Ultrasound Disease Assessment Study (CUDAS) and Busselton Population Health Survey) on the basis of body mass index (BMI). 292 obese (BMI $\geq 30 \mathrm{~kg} / \mathrm{m}^{2}$ ) and 371 lean $\left(\mathrm{BMI}<25 \mathrm{~kg} / \mathrm{m}^{2}\right.$ ) subjects were studied. Methods: Blood pressure and anthropometric measurements were collected from all participants, as well as a fasting venous blood sample. Biochemical measurements (high-density lipoprotein (HDL)and low-density lipoprotein-cholesterol, triglycerides) and PPAR $\gamma 2$ Pro12Ala genotype were also determined.

Results: Obese Pro/Ala and Ala/Ala subjects had lower levels of HDL-cholesterol $(P=0.032)$ and a trend towards higher levels of triglycerides $(P=0.055)$ compared with obese Pro/Pro subjects. In the obese group, the Ala allele was significantly associated with the presence of combined hyperlipidaemia (odds ratio $=2.33, P=0.042$ ). There was no significant difference in the frequency of the polymorphism between lean and obese groups $(P=0.069)$. No association was observed between Pro12Ala genotype and obesity, blood pressure or diabetes in either group.

Conclusions: Obese carriers of the Pro12Ala polymorphism have a greater risk of developing combined hyperlipidaemia, possibly due to impaired activation of PPAR $\gamma$ target genes. The Pro12Ala polymorphism is not directly associated with obesity, hypertension or diabetes in this population.
\end{abstract}

European Journal of Endocrinology $144277-282$

\section{Introduction}

Peroxisome proliferator-activated receptors (PPARs) are members of the nuclear hormone receptor superfamily. There are three types of PPAR and, of these, PPAR $\gamma$ has been shown to regulate adipocyte differentiation and lipid metabolism through the activation of adipocytespecific genes (1). PPAR $\gamma$ controls the transcription of target genes by the formation of a heterodimeric complex with retinoid $\mathrm{X}$ receptors, and this complex binds to specific PPAR $\gamma$ response elements in the promoter regions of these genes (2). Forced expression of PPAR $\gamma$ in fibroblasts stimulates differentiation into adipocytes (3).

Rare gain-of-function (mutant alleles directing overexpression of normal gene products) and dominant negative mutations in PPAR $\gamma$ have provided insight into its biological function in vivo. A Pro115Gln PPAR $\gamma$ mutant is associated with excessive adipose tissue accumulation through an intrinsic increase in adipogenic activity (4). Dominant negative PPAR $\gamma$ mutations are associated with severe insulin resistance, hypertension and alterations in lipid profile (low highdensity lipoprotein (HDL), high triglycerides) (5).

Alternative promoter regions within the PPAR $\gamma$ gene allow the formation of three PPAR $\gamma$ isoforms: PPAR $\gamma 1$, $\gamma 2$ and $\gamma 3$. While PPAR $\gamma 1$ mRNA is found in a wide range of tissues (including heart, liver, skeletal muscle and adipose tissue), PPAR $\gamma 2$ is most abundant in adipose tissue (6). PPAR $\gamma 3$ is expressed in macrophages, colon epithelium and adipose tissue (7). PPAR $\gamma 2$ contains 30 additional amino acids at its N-terminus, which may 
confer a greater ligand-independent activation function (augmented by insulin) upon this isoform (8). PPAR $\gamma 2$ expression is increased in adipose tissue taken from obese subjects compared with lean subjects, and is reduced during weight loss (6).

A common polymorphism (frequency approximately 0.12 in Caucasians) occurs in the PPAR $\gamma 2$-specific exon B (9). At position 34, a C to G substitution causes an amino acid change from a proline to an alanine at codon 12 (Pro12Ala). Functionally, this Ala variant has been shown to have a reduced affinity for the response element and a lower capacity for activating target genes (10).

This polymorphism has been previously studied for association with obesity and non-insulin-dependent diabetes mellitus. Results have been inconsistent with respect to body mass index (BMI) (10-15), blood lipid profile $(10,11,14)$ and insulin sensitivity $(10,13,14$, 16-18).

It was the aim of this study to clarify whether the $\operatorname{PPAR} \gamma 2$ Ala allele is associated with obesity or altered cardiovascular risk profile (visceral adiposity, blood pressure, diabetes and blood lipids) in a large group of Caucasian Western Australians.

\section{Subjects and methods}

Subjects were selected from two populations: the Carotid Ultrasound Disease Assessment Study (CUDAS) (19) and the Busselton Population Health Survey (20). These two populations were predominantly Caucasian and were collected from the same region of Western Australia.

The CUDAS group was composed of original participants in the 1989 Australian National Heart Foundation Perth Risk Factor Prevalence Survey, a random electoral survey from the Perth metropolitan area. From this survey, all subjects classified as obese (BMI $\geq 30 \mathrm{~kg} / \mathrm{m}^{2} ; \quad n=188$ ) were genotyped for the Pro12Ala polymorphism, as were a randomly selected group of lean controls (BMI $<25 \mathrm{~kg} / \mathrm{m}^{2} ; n=271$ ). BMI was the only selection criterion for genotyping.

Subjects from the Busselton Population Health Survey were studied as part of a cross-sectional community study in 1994. From 104 families with two or more overweight siblings (BMI $>25 \mathrm{~kg} / \mathrm{m}^{2}$ ), one obese (BMI $\geq 30 \mathrm{~kg} / \mathrm{m}^{2}$ ) sibling was randomly selected for genotyping. A group of 100 lean controls with similar age and sex distribution was also studied.

CUDAS and Busselton groups were both selected on the basis of BMI and did not differ significantly with respect to age, sex or allele frequency (data not shown). The obese and lean groups from each population were combined to form larger groups of 292 obese and 371 lean subjects. All subjects gave written informed consent. The study protocol was approved by the Institutional Ethics Committee of the University of Western Australia, the Sir Charles Gairdner Research
Institutional Ethics Committee and the Busselton Population Medical Research Foundation.

A self-administered questionnaire was used to report the prevalence of smoking and diabetes. Resting blood pressures and anthropometric measurements (height, weight, waist and hip circumferences) were taken from all subjects. A fasting venous blood sample was collected for lipid measurements. Triglycerides, HDLcholesterol and total cholesterol were determined using a Hitachi 747 autoanalyser. Low-density lipoprotein (LDL)-cholesterol was calculated by the method of Friedewald et al. (21).

A salt/phenol/chloroform method was used to isolate the genomic DNA from leukocytes. Mutagenically separated PCR was performed using two different length allele-specific downstream primers (P1 and P2), and a common upstream primer (P3) (22). P1 (5' GTGTATCAGTGAAGGAATCGCTTTCTTG-3') was specific for the $\mathrm{C}$ allele (Pro); and primer P2 (5'-TTGTGATATGTTTGCAGACAAGGTATCAGTG AAGGAATCGCTTTGTGC-3') bound to the $G$ allele (Ala). The upstream primer (P3) was 5'TTTCTGTGTTTATTCCCATCTCTCCC-3'. Bases underlined and in bold type indicate the location of mismatches to maintain the specificity of the two separate amplification reactions (22).

DNA (40 ng) was added to a $25 \mu \mathrm{l}$ reaction mix containing $3 \mathrm{mM} \mathrm{MgCl} 2,10 \mathrm{pmol} \mathrm{P} 1,5 \mathrm{pmol} \mathrm{P} 2$ and 10 pmol P3. The PCR conditions were: an initial denaturation of $3 \mathrm{~min}$ at $94{ }^{\circ} \mathrm{C}$; followed by 35 cycles of denaturation at $94{ }^{\circ} \mathrm{C}$ for $45 \mathrm{~s}$, annealing at $62{ }^{\circ} \mathrm{C}$ for $45 \mathrm{~s}$, and extension at $72{ }^{\circ} \mathrm{C}$ for $45 \mathrm{~s}$; then a final extension step of $3 \mathrm{~min}$ at $72^{\circ} \mathrm{C}$. A $230 \mathrm{bp}$ product identified the Pro allele, and the Ala-specific product was $250 \mathrm{bp}$. One example of each genotype was sequenced to check for correct detection of the polymorphism.

Statistical analysis was performed using MINITAB (version 12.1) and InStat (version 3.00) software. Chisquare and Fisher's exact test were used to compare the categorical variables of sex, Pro12Ala genotype, smoking and diabetes between groups. Continuous variables were tested for normality according to the Kolmogorov-Smirnov test, and data sets not normally distributed (age, total cholesterol, HDL-cholesterol, LDL-cholesterol, triglycerides, systolic blood pressure, diastolic blood pressure, BMI and waist-to-hip ratio) were $\log _{10^{-}}$transformed. Variables normalised by $\log _{10^{-}}$ transformation (total cholesterol, HDL-cholesterol, LDL-cholesterol and triglycerides) were then compared using unpaired two-tailed Student's t-tests, and the significance level was $P<0.05$. Data sets not normally distributed after $\log _{10}$-transformation (age, systolic blood pressure, diastolic blood pressure, BMI and waist-to-hip ratio) were compared using the MannWhitney U test. A general linear model was used to control for the variables of age, sex, BMI, smoking and diabetes where appropriate. 
Table 1 Biochemical and anthropometric data for obese and lean groups. Data are presented as means \pm S.D.

\begin{tabular}{lccr}
\hline & Obese $(n=292)$ & Lean $(n=371)$ & $P$ \\
\hline Men & 145 & 180 & \\
Women & 147 & 191 & \\
Age (years) & $54.8 \pm 12.0$ & $51.6 \pm 13.3$ & 0.0011 \\
Total cholesterol $(\mathrm{mmol} / \mathrm{l})$ & $5.76 \pm 0.98$ & $5.43 \pm 0.99$ & $<0.0001$ \\
HDL-cholesterol (mmol/l) & $1.15 \pm 0.29$ & $1.50 \pm 0.39$ & $<0.0001$ \\
LDL-cholesterol (mmol/l) & $3.82 \pm 0.87$ & $3.47 \pm 0.89$ & $<0.0001$ \\
Triglycerides (mmol/) & $1.72 \pm 0.87$ & $1.01 \pm 0.54$ & $<0.0001$ \\
Systolic blood pressure $(\mathrm{mmHg})$ & $136 \pm 19$ & $122 \pm 17$ & $<0.001$ \\
Diastolic blood pressure $(\mathrm{mmHg})$ & $84 \pm 10$ & $76 \pm 10$ & $<0.0001$ \\
BMl (kg/m $\left.{ }^{2}\right)$ & $32.9 \pm 2.6$ & $22.0 \pm 1.9$ & $<0.0001$ \\
BMl range $\left(\mathrm{kg} / \mathrm{m}^{2}\right)$ & $30.0-43.4$ & $16.4-25.0$ & 0.089 \\
Waist-to-hip ratio & $0.89 \pm 0.09$ & $171(46 \%)$ & 0.009 \\
Smoking history $(n)(\%)$ & $154(53 \%)$ & $3(1 \%)$ & \\
Diabetes $(n)(\%)$ & $11(4 \%)$ & & \\
\hline
\end{tabular}

A binary logistic regression model was used to test for the association of Pro12Ala genotype and combined hyperlipidaemia, controlling for the risk factors of male gender, age, smoking, diabetes, systolic blood pressure and BMI.

\section{Results}

The biochemical and anthropometric results for the 292 obese (BMI $\geq 30 \mathrm{~kg} / \mathrm{m}^{2}$ ) and 371 lean controls $\left(\right.$ BMI $<25 \mathrm{~kg} / \mathrm{m}^{2}$ ) are shown in Table 1 . The obese group had significantly higher total plasma cholesterol, LDL-cholesterol, triglycerides, blood pressure, waist-tohip ratio and lower HDL-cholesterol than the group of lean controls (all $P<0.0001$ ). The obese subjects were significantly older than the lean controls $(54.8 \pm 12.0$ vs $51.6 \pm 13.3$ years (mean age \pm s.D.), $P=0.0011$ ) and reported a higher prevalence of diabetes $(4 \%$ vs $1 \%, \chi^{2}=6.919, \mathrm{df}=1, P=0.009$ ).

All genotype groups obeyed the Hardy-Weinberg equilibrium (Table 2). The frequency of the Pro12Ala polymorphism (f(Ala)) did not differ significantly between the obese group and the lean controls $\left(\mathrm{f}(\text { Ala })_{\text {obese }}=0.145 \quad\right.$ vs $\quad \mathrm{f}(\text { Ala })_{\text {lean }}=0.129, \quad \chi^{2}=$ 5.362, $\mathrm{df}=2, P=0.069$ ).

Table 2 Prevalence of the Pro12Ala polymorphism in CUDAS and Busselton populations.

\begin{tabular}{llccccc}
\hline & & \multicolumn{5}{c}{ Genotype } \\
\cline { 5 - 6 } Population & Group & $\boldsymbol{n}$ & Pro/Pro & Pro/Ala & Ala/Ala & f(Ala) \\
\hline \multirow{2}{*}{ CUDAS } & Obese & 188 & 136 & 45 & 7 & 0.157 \\
& Lean & 271 & 205 & 64 & 2 & 0.125 \\
Busselton & Obese & 104 & 79 & 24 & 1 & 0.126 \\
& Lean & 100 & 72 & 28 & 0 & 0.140 \\
Total & Obese & 292 & 215 & 69 & 8 & 0.145 \\
& Lean & 371 & 277 & 92 & 2 & $0.129^{*}$
\end{tabular}
${ }^{*}$ No significant difference for Ala allele frequency between obese and lean
groups $\left(\chi^{2}=5.362, \mathrm{df}=2, P=0.069\right)$.
Due to the small number of homozygotes for the polymorphism, Ala/Ala individuals were included with the Pro/Ala group so that genotype was examined as a dichotomous variable (presence or absence of the polymorphism) (Table 3). In the lean group, the presence of the Ala allele was not associated with differences in BMI, waist-to-hip ratio, blood lipids, blood pressure or prevalence of diabetes. Obese Pro/Ala and Ala/Ala subjects had higher triglycerides and lower HDL-cholesterol compared with obese Pro/Pro subjects (triglycerides: $1.76 \pm 0.34$ vs $1.54 \pm 0.33 \mathrm{mmol} / \mathrm{l}$, $P=0.039$; HDL-cholesterol: $1.07 \pm 0.13$ vs $1.16 \pm$ $0.14 \mathrm{mmol} / \mathrm{l}, P=0.011)$. When these results were adjusted for covariates (age, sex, BMI, smoking and diabetes) using a general linear model, the association between the Ala allele and HDL-cholesterol levels remained significant $(P=0.032)$, while the difference in triglyceride levels between genotypes was of borderline significance $(P=0.055)$.

The obese group was further examined by stratification according to combined hyperlipidaemia status. An individual was classed as hyperlipidaemic according to the following criteria: total cholesterol $>5.2 \mathrm{mmol} / \mathrm{l}$, LDL-cholesterol $>3.5 \mathrm{mmol} / \mathrm{l}$ and triglycerides $>2.3 \mathrm{mmol} / \mathrm{l}$ (suggested clinical thresholds for combined hyperlipidaemia according to the European Atherosclerosis Society International Task Force for Prevention of Coronary Heart Disease) (23). This hyperlipidaemic group comprised 28 individuals (16 Pro/Pro and 12 Pro/Ala - none were Ala/Ala). The unadjusted odds ratio for association of the Ala allele with combined hyperlipidaemia was 2.30 (95\% confidence interval (CI), 1.03-5.11; $P=0.044$, Fisher's exact test).

A logistic regression model (Table 4) was used to adjust the odds ratio for combined hyperlipidaemia and the presence of the Ala allele, while controlling for other known risk factors (23). Male gender, smoking and diabetes were analysed as categorical variables, while age, systolic blood pressure and BMI were included in the model as continuous variables. The 
Table 3 Biochemical and anthropometric data for obese and lean subjects according to Pro12Ala genotype. Data are presented as means \pm S.D.

\begin{tabular}{|c|c|c|c|c|c|c|}
\hline & \multicolumn{3}{|c|}{ Obese subjects ( $n=292)$} & \multicolumn{3}{|c|}{ Lean subjects $(n=371)$} \\
\hline & $\begin{array}{l}\text { Pro/Pro } \\
(n=215)\end{array}$ & $\begin{array}{l}\text { Pro/Ala and Ala/Ala } \\
\qquad(n=77)\end{array}$ & $P$ & $\begin{array}{l}\text { Pro/Pro } \\
(n=277)\end{array}$ & $\begin{array}{l}\text { Pro/Ala and Ala/Ala } \\
\qquad(n=94)\end{array}$ & $P$ \\
\hline Men/women & $102 / 113$ & $43 / 34$ & & $132 / 145$ & $48 / 46$ & \\
\hline Age (years) & $54.9 \pm 12.2$ & $54.5 \pm 11.6$ & 0.78 & $51.9 \pm 13.1$ & $50.5 \pm 14.1$ & 0.32 \\
\hline Total cholesterol $(\mathrm{mmol} / \mathrm{l})$ & $5.75 \pm 0.97$ & $5.79 \pm 1.04$ & 0.76 & $5.38 \pm 1.21$ & $5.24 \pm 1.19$ & 0.22 \\
\hline HDL-cholesterol (mmol//) & $1.16 \pm 0.14$ & $1.07 \pm 0.13$ & $0.011^{*}$ & $1.50 \pm 0.38$ & $1.50 \pm 0.44$ & 0.41 \\
\hline LDL-cholesterol (mmol/l) & $3.72 \pm 1.25$ & $3.71 \pm 1.31$ & 0.98 & $3.50 \pm 0.91$ & $3.37 \pm 0.81$ & 0.13 \\
\hline Triglycerides (mmol/l) & $1.54 \pm 0.33$ & $1.76 \pm 0.34$ & $0.039^{\star}$ & $1.02 \pm 0.57$ & $0.98 \pm 0.46$ & 0.77 \\
\hline Systolic blood pressure (mmHg) & $137 \pm 20$ & $135 \pm 19$ & 0.45 & $122 \pm 16$ & $124 \pm 18$ & 0.40 \\
\hline Diastolic blood pressure $(\mathrm{mmHg})$ & $84 \pm 10$ & $86 \pm 10$ & 0.20 & $76 \pm 10$ & $76 \pm 10$ & 0.88 \\
\hline BMI $\left(\mathrm{kg} / \mathrm{m}^{2}\right)$ & $32.9 \pm 2.6$ & $32.9 \pm 2.6$ & 0.89 & $22.0 \pm 1.8$ & $22.1 \pm 2.0$ & 0.47 \\
\hline Waist-to-hip ratio & $0.89 \pm 0.89$ & $0.90 \pm 0.08$ & 0.25 & $0.81 \pm 0.08$ & $0.81 \pm 0.08$ & 0.73 \\
\hline Diabetes $(n)(\%)$ & $8(4 \%)$ & $3(4 \%)$ & 0.99 & $2(1 \%)$ & $1(1 \%)$ & 0.99 \\
\hline
\end{tabular}

* $P<0.05$.

adjusted odds ratio for association of the Ala allele and hyperlipidaemia in the obese group was 2.33 (95\% CI, $1.03-5.29 ; P=0.042$ ).

\section{Discussion}

The main finding of this study is that obese carriers of the PPAR $\gamma 2$ Ala allele were found to have a more atherogenic lipid profile (characterised by lower HDLcholesterol levels, and a trend towards higher triglycerides) compared with obese Pro/Pro individuals. Both lower HDL and higher triglycerides are known risk factors for coronary artery disease $(24,25)$, suggesting that the presence of the Ala allele may exacerbate the altered lipid profile common in obesity. The presence of the Ala allele was the only significant predictor of combined hyperlipidaemia in obese subjects when other risk factors such as blood pressure, smoking, BMI, male gender, age and diabetes were taken into account. These results were not seen in the lean group.

In this study, there was no evidence to suggest that the Pro12Ala polymorphism was a predisposing factor for obesity. Allele frequencies were similar between the obese group and lean controls, and the

Table 4 Logistic regression model for association of PPAR $\gamma 2$ Ala allele with combined hyperlipidaemia* in obese subjects.

\begin{tabular}{lccc}
\hline Predictor variables & Odds ratio & $\mathbf{9 5 \%} \mathbf{C l}$ & $\boldsymbol{P}$ \\
\hline Ala allele & 2.33 & $1.03-5.29$ & 0.042 \\
Systolic blood pressure & 1.02 & $1.00-1.04$ & 0.087 \\
Smoking history & 1.67 & $0.70-3.99$ & 0.25 \\
BMl & 1.09 & $0.93-1.28$ & 0.27 \\
Male gender & 1.60 & $0.66-3.87$ & 0.30 \\
Age & 0.99 & $0.96-1.03$ & 0.77 \\
Diabetes & 0.91 & $0.11-7.84$ & 0.93 \\
\hline
\end{tabular}

* Combined hyperlipidaemia is defined as: total cholesterol $>5.2 \mathrm{mmol} / \mathrm{l}$, $\mathrm{LDL}$-cholesterol $>3.5 \mathrm{mmol} / \mathrm{l}$ and triglycerides $>2.3 \mathrm{mmol} / \mathrm{l}$ (23). The PPAR $\gamma 2$ Ala allele, smoking history, male gender and diabetes are included in the model as categorical variables. Systolic blood pressure, BMI and age are given as continuous variables.
Ala variant was not associated with higher BMI or waist-to-hip ratio within either group. Also, no differences between genotypes were observed for total cholesterol, LDL-cholesterol, blood pressure or frequency of diabetes in obese or lean subjects.

The association between Pro12Ala genotype, HDLcholesterol and triglycerides in a large group of subjects has not been described previously. In a group of 57 extremely obese men, Beamer et al. (11) found that subjects with the Ala allele had lower HDL and higher triglyceride levels compared with Pro/Pro subjects. This effect was not observed in 112 extremely obese women or in a cohort of 517 lean to moderately obese individuals (BMI $18.6-43.2 \mathrm{~kg} / \mathrm{m}^{2}$ ). Our positive observations were seen in a much larger group of obese subjects $(n=292)$.

A population study of 973 elderly Finnish subjects (10) found that Ala/Ala individuals $(n=20)$ had significantly higher HDL-cholesterol and lower triglycerides at follow-up compared with Pro/Pro and Pro/ Ala subjects. However, these subjects were of lower BMI than the obese subjects studied here (mean BMI 25-27 vs $32.9 \pm 2.6 \mathrm{~kg} / \mathrm{m}^{2}$ ), and therefore they may be more equivalent to our lean group. Furthermore, in these subjects there appeared to be no difference in HDLcholesterol between Pro/Pro and Pro/Ala subjects $(1.27 \pm 0.01$ vs $1.24 \pm 0.02 \mathrm{mmol} / \mathrm{l})$, which is concordant with our findings in subjects of a similar BMI.

Another large population-based study (14) observed higher levels of total cholesterol, LDL-cholesterol and apolipoprotein B in carriers of the Ala allele compared with Pro/Pro individuals. Again, the mean BMI for each of the genotypes was much lower than that of our obese group (mean BMI $25-26 \mathrm{~kg} / \mathrm{m}^{2}$ ), so these results are not directly comparable with the results seen in obese individuals.

The higher rate of combined hyperlipidaemia seen in the obese subjects with the polymorphism may be due to an intrinsic reduction in PPAR $\gamma 2$ activity. In vitro, 
the Ala isoform of PPAR $\gamma 2$ has been shown to be less effective at activating target genes $(10,26)$. One of these target genes is lipoprotein lipase (LPL) (27). LPL hydrolyses triglycerides in circulating chylomicrons and very low-density lipoproteins, releasing fatty acids, chylomicron remnants and LDL-cholesterol. LPL activity has also been shown to correlate strongly with plasma HDL levels (28). Similar alterations in blood lipid profile (increased triglycerides, decreased HDL) are seen in heterozygous LPL deficiency (29), an effect which is more pronounced in obese individuals (30). The effect of the Ala allele on blood lipid profile might only be revealed in the obese state due to the larger adipose tissue mass and therefore relative abundance of the fat-specific PPAR $\gamma 2$ isoform.

In conclusion, the PPAR $\gamma 2$ Pro12Ala polymorphism was found to be significantly associated with a change in lipid profile in obese carriers. For these subjects, this common polymorphism may constitute a novel genetic risk factor for combined hyperlipidaemia and cardiovascular disease.

\section{Acknowledgements}

This study was supported by grants-in-aid from the National Heart Foundation of Australia (NHF Grant G97P 5002). Funding for the 1994 Busselton Survey was provided by Healthway, the Western Australian Health Promotion Foundation. The authors thank the Busselton Population Medical Research Foundation for access to the survey data and the community of Busselton for their support.

\section{References}

1 Spiegelman BM \& Flier JS. Adipogenesis and obesity: rounding out the big picture. Cell 199687 377-389.

2 Tontonoz P, Hu E, Graves RA, Budavari AI \& Spiegelman BM. mPPAR $\gamma$ 2: tissue-specific regulator of an adipocyte enhancer. Genes and Development 19948 1224-1234.

3 Tontonoz P, Hu E \& Spiegelman BM. Stimulation of adipogenesis in fibroblasts by PPAR $\gamma 2$, a lipid-activated transcription factor. Cell 199479 1147-1156.

4 Ristow M, Müller-Wieland D, Pfieffer A, Krone W \& Kahn CR Obesity associated with a mutation in a genetic regulator of adipocyte differentiation. New England Journal of Medicine 1998 339 953-959.

5 Barosso I, Gurnell M, Crowley VEF, Agostini M, Schwabe JW, Soos MA et al. Dominant negative mutations in human PPAR $\gamma$ associated with severe insulin resistance, diabetes mellitus and hypertension. Nature $1999 \mathbf{4 0 2} 880-883$.

6 Vidal-Puig A, Considine RV, Jimenez-Liñan M, Werman A, Pories WJ, Caro JF et al. Peroxisome proliferator-activated receptor gene expression in human tissues: effects of obesity, weight loss and regulation by insulin and glucocorticoids. Journal of Clinical Investigation $1997992416-2422$.

7 Fajas L, Fruchart J-C \& Auwerx J. PPAR $\gamma 3$ mRNA: a distinct subtype transcribed from an independent promoter. FEBS Letters 1998438 55-60.

8 Werman A, Wollenberg A, Solanes G, Bjørkbæk C, Vidal-Puig AJ \& Flier JS. Ligand-independent activation domain in the Nterminus of peroxisome proliferator-activated receptor $\gamma$
(PPAR $\gamma)$. Journal of Biological Chemistry 1997272 2023020235.

9 Yen CJ, Beamer BA, Negri C, Silver K, Brown KA \& Yarnall DP. Molecular screening of the human peroxisome proliferatoractivated receptor $\gamma(\mathrm{hPPAR} \gamma)$ gene in diabetic Caucasians: identification of a Pro12Ala missense mutation. Biochemical and Biophysical Research Communications 1997241 270-274.

10 Deeb SS, Fajas L, Nemoto M, Pihlajamäki J, Mykkänen L, Kuusisto J et al. Pro12Ala substitution in PPAR $\gamma 2$ associated with decreased receptor activity, lower body mass index and improved insulin sensitivity. Nature Genetics 199820 284-287.

11 Beamer BA, Yen C-J, Andersen RE, Muller D, Elahi D, Cheskin LJ et al. Association of the Pro12Ala variant in the peroxisome proliferator-activated receptor- $\gamma 2$ gene with obesity in two Caucasian populations. Diabetes 199847 1806-1808.

12 Ek J, Urhammer SA, Sørensen TIA, Andersen T, Auwerx J \& Pedersen O. Homozygosity of the Pro12Ala variant of the peroxisome proliferation-activated receptor- $\gamma 2(P P A R-\gamma 2)$ : divergent modulating effects on body mass index in obese and lean Caucasian men. Diabetologia 199942 892-895.

13 Valve R, Sivenius K, Miettinen R, Pihlajamäki J, Risannen A, Deeb SS et al. Two polymorphisms in the peroxisome proliferatoractivated receptor- $\gamma$ gene are associated with severe overweight among obese women. Journal of Clinical Endocrinology and Metabolism 199984 3708-3712.

14 Meirhaeghe A, Fajas L, Helbecque N, Cottel D, Auwerx J, Deeb SS et al. Impact of the peroxisome proliferator activated receptor $\gamma 2$ Pro12Ala polymorphism on adiposity, lipids and non-insulindependent diabetes mellitus. International Journal of Obesity 2000 24 195-199.

15 Cole SA, Mitchell BD, Hsueh W-C, Pineda P, Beamer BA, Shuldiner AR et al. The Pro12Ala variant of peroxisome proliferator-activated receptor- $\gamma 2$ (PPAR- $\gamma 2$ ) is associated with measures of obesity in Mexican Americans. International Journal of Obesity $2000 \mathbf{2 4} 522-524$.

16 Hara K, Okada T, Tobe K, Yasuda K, Mori Y, Kadowaki H et al. The Pro12Ala polymorphism in PPAR $\gamma 2$ may confer resistance to type 2 diabetes. Biochemical and Biophysical Research Communications $2000271212-216$.

17 Ringel J, Engeli S, Distler A \& Sharma AM. Pro12Ala missense mutation of the peroxisome proliferator-activated receptor $\gamma$ and diabetes mellitus. Biochemical and Biophysical Research Communications 1999254 450-453.

18 Mancini FP, Vaccaro O, Sabatino L, Tufano A, Rivellese AA, Riccardi G et al. Pro12Ala substitution in the peroxisome proliferator-activated receptor- $\gamma 2$ is not associated with type 2 diabetes. Diabetes $1999 \mathbf{4 8} 1466-1468$.

19 McQuillan BM, Beilby JP, Nidorf M, Thompson PL \& Hung J. Hyperhomocysteinaemia but not the C677T mutation of methelenetetrahydrofolate reductase is an independent risk determinant of carotid wall thickening: the Perth Carotid Ultrasound Disease Assessment Study (CUDAS). Circulation $1999992383-2388$.

20 Knuiman MW, Jamrozik K, Welborn TA, Bulsara MK, Divitni ML \& Whittal DE. Age and secular trends in risk factors for cardiovascular disease in Busselton. Australian Journal of Public Health 199519 375-382.

21 Friedewald WT, Levy RI \& Fredrickson DS. Estimation of the concentration of low-density lipoprotein cholesterol in plasma, without the use of preparative ultrafuge. Clinical Chemistry 1972 18 499-502.

22 Rust S, Funke H \& Assmann G. Mutagenically separated PCR (MS-PCR): a highly specific one step procedure for easy mutation detection. Nucleic Acids Research 199321 3623-3629.

23 Betteridge DJ \& Kahn M. Review of new guidelines for management of dyslipidaemia. In Ballière's Clinical Endocrinology and Metabolism: International Practice and Research, pp 867-890. Ed. DJ Betteridge. London: Ballière Tindall, 1995.

24 Assmann G \& Schulte H. Relation of high-density lipoprotein cholesterol and triglycerides to incidence of atherosclerotic 
coronary artery disease (the PROCAM experience). American Journal of Cardiology 1992 70 733-737.

25 Manninen V, Tenkanen L, Koskinen P, Huttunen JK, Mänttäri M, Heinonen OP et al. Joint effects of serum triglyceride and LDL cholesterol and HDL cholesterol concentrations on coronary heart disease risk in the Helsinki heart study. Circulation $1992 \mathbf{8 5}$ $37-45$.

26 Masugi J, Tamori Y, Mori H, Koike T \& Kasuga M. Inhibitory effect of a proline-to-alanine substitution at codon 12 of peroxisome proliferator-activated receptor- $\gamma 2$ on thiazolidinedione-induced adipogenesis. Biochemical and Biophysical Research Communications 2000268 178-182.

27 Schoonjans K, Peinado-Onsurbe J, Lefebvre A-M, Heyman RA, Briggs M, Deeb S et al. PPAR $\alpha$ and PPAR $\gamma$ activators direct a distinct tissue-specific transcriptional response via a PPRE in the lipoprotein lipase gene. EMBO Journal 199615 5336-5348.
28 Kekki M. Lipoprotein lipase action determining plasma high density lipoprotein lipase cholesterol level in adult normolipidaemics. Atherosclerosis 198037 143-150.

29 Wilson DE, Emi M, Iverius P-H, Hata A, Wu LL, Hillas E et al. Phenotypic expression of heterozygous lipoprotein lipase deficiency in the extended pedigree of a proband homozygous for a missense mutation. Journal of Clinical Investigation $199086735-$ 750 .

30 Julien P, Vohl M-C, Gaudet D, Gagné C, Lévesque G, Després J-P. et al. Hyperinsulinaemia and abdominal obesity affect the expression of hypertriglyceridaemia in heterozygous familial lipoprotein lipase deficiency. Diabetes $1997 \mathbf{4 6} 2063-2068$.

Received 23 August 2000

Accepted 23 October 2000 